\title{
O IMPACTO POSITIVO DO USO DAS BOAS PRÁTICAS DE FABRICAÇÃO EM UMA INDÚSTRIA DE ALIMENTOS PET
}

\author{
THE POSITIVE IMPACT OF THE USE OF GOOD MANUFACTURING PRACTICES \\ IN A PET FOOD INDUSTRY
}

Mário Henrique Marconi - mariomarconi70@gmail.com Angelita Moutin Segoria Gasparotto - angelita.gasparotto@ fatectq.edu.br Faculdade de Tecnologia de Taquaritinga (FATEC) - SP - Brasil

DOI: 10.31510/infa.v15i1.340

\section{RESUMO}

As ações de controle sanitário na área de alimentos devem ter constante aperfeiçoamento, para garantir a qualidade dos mesmos. O objetivo geral deste estudo foi analisar e identificar os impactos da implantação das Boas Práticas de Fabricação em uma indústria de alimentos para cães e gatos, visando destacar os benefícios gerados pela sua implantação. Mostrar, através dos meios de avaliação e monitoramento, a eficiência e eficácia que as BPF`s proporcionam. Além disso, são considerados objetivos secundários deste estudo a elaboração do manual de Boas Práticas de Fabricação, visando prover a formalização e a padronização de tais práticas já realizadas pela empresa estudada, e a adequação de novos conceitos a serem analisados.

Palavras chaves: Controle. Impactos. Qualidade. Monitoramento.

\begin{abstract}
The sanitary control actions in the food area should be improved to ensure their quality. The overall objective of this study was to analyze and identify the impacts of the implantation of Good Manufacturing Practices in a dog and cat food industry, with a view to highlighting the benefits generated by your deployment. To show, through the means of evaluation and monitoring, the efficiency and effectiveness that GMPs provide. In addition, secondary objectives of this study are the preparation of the Good Manufacturing Practices manual, aiming to provide formalization and standardization of such practices already carried out by the company studied, and the adequacy of new concepts to be analyzed.
\end{abstract}

Keywords: Control. Impacts. Quality. Monitoring.

\section{INTRODUÇÃO}

A utilização das Boas Práticas de Fabricação (BFP) garante que os alimentos cheguem até o mercado consumidor em condições higiênicas sanitárias adequadas necessárias para o 
atendimento do que rege a legislação em vigor. Assim sendo, o programa BPF trata-se de uma ferramenta de qualidade (GOMES et al , 2006).

Devido a isto, a legislação brasileira dispõe de uma regulamentação técnica de Boas Práticas, que abrange os cuidados necessários no manuseio dos alimentos, que se caso não for aplicada configura infração de natureza sanitária, sujeitando a empresa varias penas que podem variar desde notificações até multas e interdição do estabelecimento. Todos os serviços de alimentação devem cumprir uma série de determinações relacionadas a todos os aspectos, processos e serviços da empresa, desde suas instalações, aquisição, armazenamento e manipulação dos alimentos até a definição de responsabilidades, documentação e registros (BRASIL, 2006).

A Resolução n²16, de 15 de setembro de 2004, da Agência Nacional de Vigilância Sanitária-ANVISA, estabelece os procedimentos de Boas Práticas em alimentação para garantir as condições higiênico-sanitárias gerais do alimento preparado para o consumo, para que as pessoas não ingerissem alimentos contaminados.

Já a INSTRUÇÃO NORMATIVA Nº 04/2007 (Art. $1^{\circ}$ ), estabelece procedimentos para todos os estabelecimentos, fabricante de produtos destinados à alimentação animal. Destina-se ainda aos fiscais federais agropecuários no exercício das ações de inspeção e fiscalização destes estabelecimentos, bem como para servir de guia às empresas do setor na elaboração e implantação do Manual de Boas Práticas de Fabricação com as informações necessárias à segurança e adequação dos alimentos para animais.

\section{METODOLOGIA DO TRABALHO}

O trabalho foi desenvolvido através de uma pesquisa qualitativa com checklist (IN 4/2007), ou seja, coleta e análises de dados registrados em uma indústria de alimentos destinados animais (cães e gatos), situada no estado de São Paulo. Esse levantamento de dados foi preenchido no período de março a agosto de 2016, como implantação do BPF.

Durante o trabalho acompanhou-se todos os processos produtivos, desde a recepção de matérias-primas até o produto final, e assim foi elaborado o Manual de Boas Práticas de Fabricação, visando sempre aplicar de forma objetiva as diretrizes e normativas que regem os setores, trazendo qualidade e segurança para o alimento.

Após ter realizado a leitura da Instrução Normativa nº 4 do Ministério da Agricultura, Pecuária e Abastecimento (MAPA), iniciou-se o processo de verificação da situação atual da 
empresa no tocante às BPF (Boas Práticas de Fabricação). Durante o período analisado realizouse a observação por todo o processo produtivo e diversas reuniões com a gerência da empresa foram feitas. Com isso foram levantadas várias sugestões de melhorias e adaptações.

Nessas reuniões, perante a necessidade de adequações e de melhorias, fez-se uma sensibilização com a direção através do diálogo, juntamente com a equipe de gestão da qualidade, e foi apresenta a importância da implantação do manual das Boas Práticas de Fabricação.

Esta sensibilização foi de grande importância, pois fez com que a empresa compreendesse a necessidade da implantação do manual, sendo ponto chave nesse processo de melhorias, adaptações e novas oportunidades de crescimento.

\section{PROGRAMA DE BOAS PRÁTICAS DE FABRICAÇÃo}

As Boas Práticas de Fabricação (BPF) são procedimentos higiênico-sanitários e operacionais aplicados em todo fluxo de produção, desde a obtenção dos ingredientes e matérias-primas até a distribuição do produto final, com o objetivo de garantir a qualidade, conformidade e segurança dos produtos destinados à alimentação animal.

Para desenvolver os conceitos propostos pela BPF é essencial ter conhecimento de alguns assuntos que são descritos no MAPA (Ministério da Agricultura, Pecuária e Abastecimento) através da Instrução Normativa $n^{\circ} 4$ (2007), para efeito de seu regulamento e pelo manual BPF da Sindirações (Sindicato Nacional da Indústria de Alimentação Animal):

- Controle de qualidade: é o conjunto de procedimentos que envolvem programação, coordenação e execução com o objetivo de verificar e assegurar a conformidade da matéria-prima, ingredientes, do rótulo e da embalagem, do produto intermediário e acabado com especificações estabelecidas;

- Procedimentos Operacionais Padrão (POP): é a descrição pormenorizada e objetiva de instruções, técnicas e operacionais, rotineiras utilizadas pelos fabricantes de produtos destinados a alimentação animal;

- Responsabilidade técnica: é o profissional habilitado, capacitado e tecnicamente competente para exercer a atividade na área de alimentos para animais e seus respectivos controles; 
- Conformidade: é o atendimento às especificações de qualidade, segurança e inocuidade descritos nos compêndios de referencia e legislação pertinentes;

- Ações corretivas: são ações tomadas diante da identificação de alguma não conformidade no processo ou produto para serem corrigidas.

- Ações preventivas: são aquelas todas para evitar que uma não conformidade ocorra;

- Rastreabilidade: é o processo de verificação de informações de ingredientes, processo e armazenamento;

- Contaminação: é a presença de substâncias ou agentes estranhos de origem biológica, química ou física que sejam considerados nocivos à saúde dos animais;

- Contaminação cruzada: é a contaminação de produto destinado à alimentação animal com outro produto, durante o processo de produção ou contaminação gerada pelo contato indevido de ingrediente, insumo, superfície, ambiente, pessoas ou produtos contaminados, que afetam a inocuidade do produto;

- Limpeza: é a remoção de qualquer tipo de resíduo indesejável;

- Higienização: é a limpeza e a desinfecção;

- Pragas: são insetos e todos os animais, tais como gatos e pássaros, capazes de contaminar direta ou indiretamente os alimentos; os pesticidas ou praguicidas são substâncias químicas ou biológicas utilizadas no controle de pragas.

Segundo Sotille (2014), definir o que queremos obter através de resultados de qualidade é muito importante para que possam existir parâmetros e métricas para a avaliação.

É comum observar a confusão entre garantia da qualidade e controle da qualidade. Desse modo, torna-se comum acompanhar equipes de garantia da qualidade executando tarefas relacionadas com o controle de qualidade.

Envolve a comparação de resultados com os padrões aplicáveis. Qualquer desvio identificado na comparação e avaliação é passível de registro de não conformidade. A não conformidade, assim que for identificada, deve seguir os passos descritos no plano para seu devido tratamento. $\mathrm{O}$ controle de qualidade permite assegurar que o produto funcione de forma correta (dentro dos padrões) e que os requisitos sejam atendidos. (SOTILLE, 2014).

É desígnio da auditoria da qualidade a avaliação e a adaptação da eficácia das disposições planejadas através da coleta e utilização da evidência. Os dados tem que ser 
objetivos, identificar e registrar as instâncias de não conformidade com os arranjos e disposições da qualidade e mostrar, quando for possível, as causas. É necessário entender que a auditoria é um exercício para coletar dados, que torna possível que uma necessidade de progresso ou de ações de correção seja encontrada. A informação que se busca é a evidência objetiva da conformidade, e não o número mais alto de não conformidades.

Os auditores deveriam ser cuidadosos com esse aspecto e, em todas as suas ações, deveriam formar esta imagem positiva da auditoria da qualidade. Caso contrário um clima para uma conversação eficaz não será encontrado (ARAUJO, 2012).

Segundo Araújo (2012), os objetivos de uma auditoria são:

- Determinação da conformidade ou não conformidade com os requisitos especificados;

- Determinação da eficácia do sistema no atendimento aos objetivos;

- Identificação do potencial de melhoria no que se refere ao sistema da qualidade;

- Atendimento dos requisitos regulamentares;

- Certificação do sistema da qualidade.

\subsection{Avaliação do Desempenho da BPF através de Auditorias}

Um dos métodos adotados para avaliação e medição de desempenho do BPF é o Checklist (IN 4/2007), cuja aplicação é feita por uma equipe composta por operadores, líderes e supervisores de todos os setores da empresa que receberam treinamentos e capacitação necessária para atuar como auditores internos.

Segundo Gouvêa (2011), Checklist ou Folha de Verificação é uma ferramenta usada para padronizar e verificar resultados de um trabalho, ou para verificar e coletar dados.

O checklist mostra um perfil dos acontecimentos, respondendo qual a frequência observada de um determinado problema. Varia conforme o setor no qual é utilizada onde pode ser elaborada para verificar as atividades já efetuadas ou as ainda a serem feitas.

É importante observar que anterior à utilização de quaisquer ferramentas de qualidade deve-se ter um fluxograma bem definido para o estudo. Trata-se da coleta dos dados, que é o início para qualquer estudo de problemas e, portanto, deve ser bem planejada, atendendo os seguintes tópicos:

- Todos devem procurar e observar a mesma fonte de problemas; 
- Deve-se estabelecer o período em que os dados serão coletados. Este período pode variar de horas, dias ou semanas;

- Devem-se construir tabelas claras e de fácil manuseio;

- O tempo de coleta dos dados deve ser suficiente, possibilitando uma coleta sistemática e honesta.

Segundo Paula (2015), podemos afirmar que um Indicador é um valor quantitativo que possibilita a empresa medir o que está sendo executado e gerenciá-la de forma adequada para atingir as metas organizacionais ou departamentais planejadas.

Como o próprio nome induz, um indicador é uma métrica que indica algo útil, relevante e que ajuda na tomada de decisões. Além de serem fundamentais para medição dos resultados, os indicadores são excelentes veículos de comunicação, pois permitem que uma organização comunique suas metas e resultados a toda a equipe, demonstrando de forma direta e objetiva o quão eficiente um processo está e como tem sido seu desempenho ao longo de um período determinado.

Os indicadores de qualidade são estruturados no número de reclamações de clientes, número de devolução de produtos, número de produtos contaminados ou, ainda, número de superfícies contaminadas. Outro indicador importante no processo é o de produtividade que pode ser formado a partir de dados de recursos como: número de funcionários, matéria-prima, gastos em energia, horas trabalhadas. No início da implantação são estabelecidos os indicadores de qualidade e produtividade, e acompanhados ao longo da execução dos trabalhos. A análise desses índices permite ao empresário visualizar o impacto do programa em pilares fundamentais para a sobrevivência das empresas no atual mercado (ALMEIDA, 2012).

Conforme descrito no Procedimento interno da indústria para Auditorias Internas (PPAI-001/017) elas serão realizadas uma vez por mês, e a partir daí é retirada as notas de cada setor contendo informações sobre organização e limpeza, controle de pragas, higienização e sanitização, organização estrutural. E conforme os resultados obtidos, análises e discussões serão realizadas pelos gestores da área para resolver as não conformidades encontradas por meio de um plano de ação que consiste na emissão de um Relatório de Não Conformidade ou Melhoria (RNC-M), no qual estão contidos o emitente e o destinatário, o setor e a descrição da ocorrência encontrada.

Mediante uma análise de causas para descobrir a causa raiz do problema, ou com as oportunidades de melhorias já identificadas, são apresentados os planos de ações com seus responsáveis. Para os auditores internos que realizam a inspeção e verificação mensal do 
checklist, é realizada uma reunião periódica para levantar informações sobre as conformidades e não conformidades apontadas e as possíveis adequações e soluções para essas ocorrências, já os colaboradores participam de uma reunião mensal para estarem cientes de todas as adequações, conformidades e não conformidades encontradas no setor, e os possíveis planos de ação que serão aplicados no setor e o que cada um deve fazer regularmente para melhorar ainda mais o desempenho e os objetivos do setor.

\section{RESULTADOS E DISCUSSÕES}

Após as analises das auditorias internas e dos indicadores da qualidade, foi elaborado checklist $\mathrm{e}$ aplicados em todos os setores da fabrica para a coleta de dados. Para melhor avaliar e discutir seus resultados foram divididos em três grupos: áreas produtivas (fábrica), áreas de apoio (Qualidade/Manutenção/Administração) e áreas comuns (estacionamento/jardinagem) (Tabela 1). Desse modo evidenciamos os impactos que o checklist de Boas Práticas de Fabricação trará nos setores de maior importância e que tem ligação direta com a qualidade e a segurança dos alimentos produzidos.

A partir daí, podem-se examinar os resultados obtidos e as oportunidades de melhorias que ainda podem ser desenvolvidas em cada questão do checklist evidenciada por acertos a uma porcentagem num total de resposta de $100 \%$ (Instrução Normativa $\mathrm{N}^{\circ} 4$, Ítem 10). Para tanto, segue abaixo a evolução das áreas (notas \%, cuja avaliação ocorreu de março a agosto de 2016).

Ilustração 1 - Projeto Boas Práticas de Fabricação: Evolução das Áreas

\begin{tabular}{|l|r|r|r|r|r|r|}
\hline \multicolumn{1}{|c|}{ Áreas } & \multicolumn{1}{|c|}{ Max } & \multicolumn{1}{c|}{ Abr } & \multicolumn{1}{c|}{ Mai } & \multicolumn{1}{c|}{ Jum } & \multicolumn{1}{c|}{ Jul } & \multicolumn{1}{c|}{ A } \\
\hline Comum & $92,30 \%$ & $100,00 \%$ & $100,00 \%$ & $100,00 \%$ & $100,00 \%$ & $100,00 \%$ \\
\hline Comum & $77,70 \%$ & $100,00 \%$ & $88,00 \%$ & $80,00 \%$ & $91,70 \%$ & $100,00 \%$ \\
\hline Comum & $81,30 \%$ & $81,00 \%$ & $70,60 \%$ & $83,00 \%$ & $93,00 \%$ & $93,00 \%$ \\
\hline Apoio & $92,90 \%$ & $92,90 \%$ & $100,00 \%$ & $92,80 \%$ & $100,00 \%$ & $100,00 \%$ \\
\hline Apoio & $93,30 \%$ & $93,00 \%$ & $92,80 \%$ & $100,00 \%$ & $100,00 \%$ & $100,00 \%$ \\
\hline Apoio & $86,70 \%$ & $100,00 \%$ & $100,00 \%$ & $92,80 \%$ & $100,00 \%$ & $100,00 \%$ \\
\hline Apoio & $97,10 \%$ & $100,00 \%$ & $100,00 \%$ & $100,00 \%$ & $100,00 \%$ & $100,00 \%$ \\
\hline Apoio & $90,90 \%$ & $100,00 \%$ & $100,00 \%$ & $100,00 \%$ & $100,00 \%$ & $100,00 \%$ \\
\hline Apoio & $80,00 \%$ & $92,30 \%$ & $100,00 \%$ & $100,00 \%$ & $100,00 \%$ & $100,00 \%$ \\
\hline Apoio & $81,30 \%$ & $81,00 \%$ & $70,60 \%$ & $83,00 \%$ & $88,80 \%$ & $88,80 \%$ \\
\hline Apoio & $86,60 \%$ & $81,30 \%$ & $88,90 \%$ & $88,20 \%$ & $100,00 \%$ & $100,00 \%$ \\
\hline Produtiva & $94,70 \%$ & $100,00 \%$ & $95,20 \%$ & $100,00 \%$ & $100,00 \%$ & $100,00 \%$ \\
\hline Produtiva & $84,20 \%$ & $90,00 \%$ & $82,60 \%$ & $82,60 \%$ & $86,40 \%$ & $95,70 \%$ \\
\hline Produtiva & $88,80 \%$ & $89,50 \%$ & $85,00 \%$ & $90,00 \%$ & $100,00 \%$ & $86,40 \%$ \\
\hline Produtiva & $84,20 \%$ & $94,40 \%$ & $81,00 \%$ & $76,00 \%$ & $95,50 \%$ & $95,50 \%$ \\
\hline Produtiva & $89,50 \%$ & $94,40 \%$ & $81,00 \%$ & $81,80 \%$ & $81,80 \%$ & $90,00 \%$ \\
\hline Produtiva & $71,40 \%$ & $93,80 \%$ & $95,20 \%$ & $90,50 \%$ & $90,90 \%$ & $95,00 \%$ \\
\hline Produtiva & $73,70 \%$ & $88,80 \%$ & $90,50 \%$ & $91,00 \%$ & $91,00 \%$ & $95,00 \%$ \\
\hline Produtiva & $90,00 \%$ & $89,50 \%$ & $100,00 \%$ & $86,00 \%$ & $95,00 \%$ & $100,00 \%$ \\
\hline Produtiva & $78,50 \%$ & $94,10 \%$ & $100,00 \%$ & $100,00 \%$ & $100,00 \%$ & $100,00 \%$ \\
\hline
\end{tabular}

Fonte: Elaborado pelo autor (2016). 


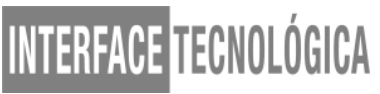

Ilustração 2 - modelo do Checklist - conforme IN 4, Ítem 10, Anexo II

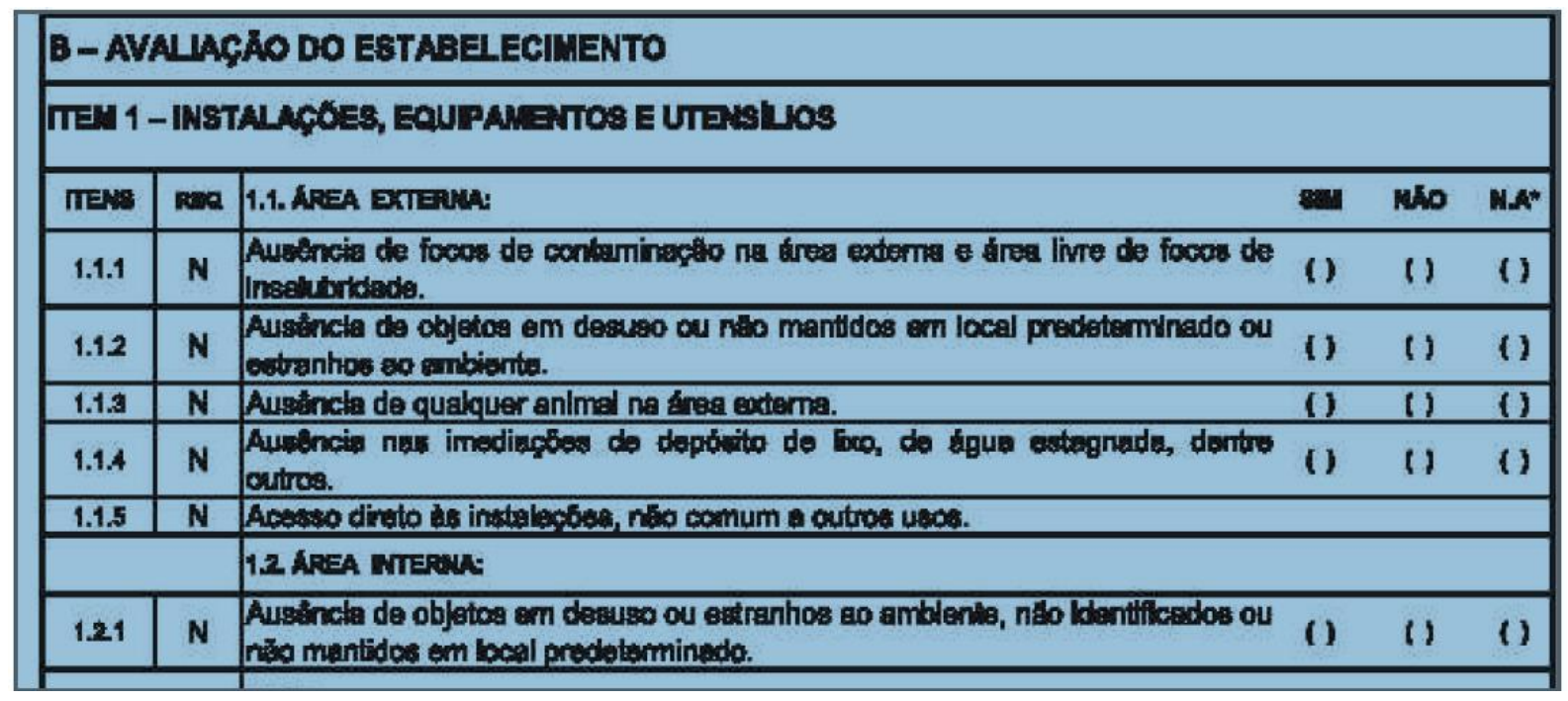

Fonte: MAPA (2017)

Neste caso, observa-se grande crescimento nas notas das áreas produtivas, onde no começo havia mais numero de ocorrências de não conformidade e que agora foram reduzidas, também há de se levar em consideração que alguns planos de ações realizados para a adequação das não conformidades apontadas ou de melhorias terão seus resultados obtidos a longo prazo; dessa forma alguns setores ainda apresentarão notas reduzidas devido a esse tempo ocioso para implantação do BPF.

Para que cada setor tenha uma iniciativa de deixar a sua área nas melhores condições possíveis dentro das diretrizes que o manual pede, o checklist possui um farol de sinalização, que indica uma porcentagem da nota atribuída ao local, conforme IN 4, Ítem 10, Anexo II (alterado IN 15/2009 - MAPA).

Ilustração 3 - modelo do Checklist - conforme IN 4, Ítem 10, Anexo II

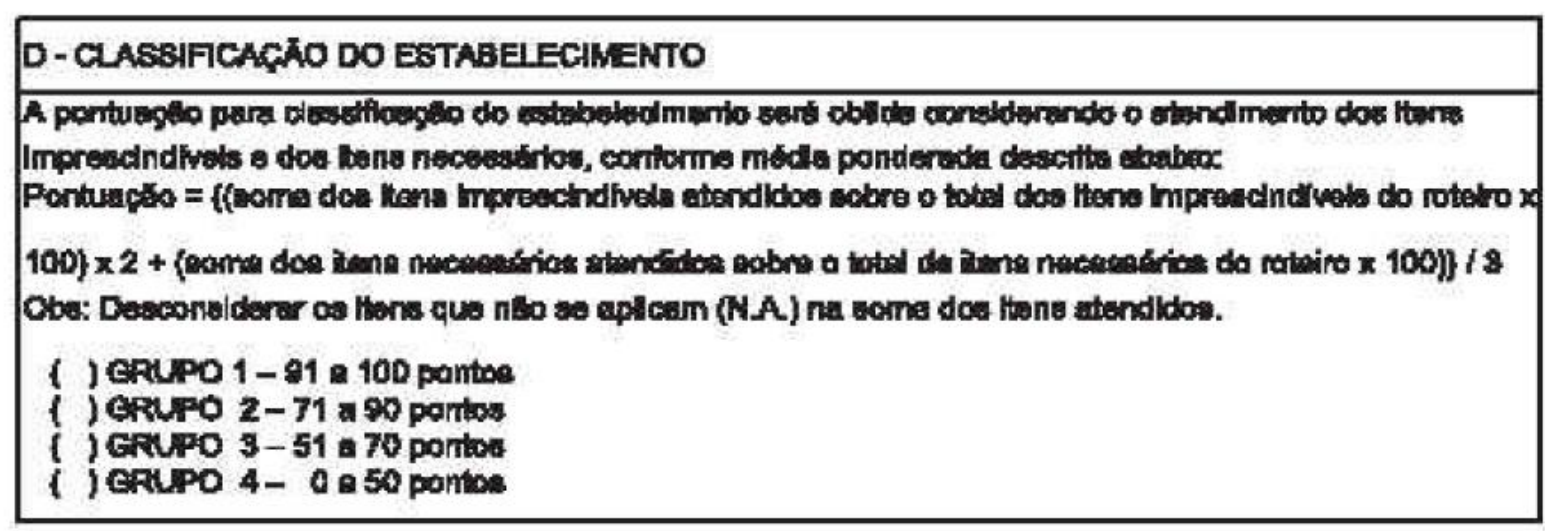

Fonte: MAPA (2017) 
O farol vermelho indica que o setor possui diversas não conformidades e não respeita as normas do BPF, tendo uma nota até $65(\%)$.

Para o farol amarelo há algumas não conformidades, e o setor necessita de cuidados e atenção, com sua nota variando entre 65,1 (\%) até 84,9 (\%).

E por fim a sinalização verde, que indica que o setor apresenta quase nenhuma não conformidade, com sua nota variando de $85(\%)$ a $100(\%)$.

Com essa indicação, o colaborador não precisará ler todo o checklist, basta apenas observar o farol e saberá a atual condição que o setor se encontra. E para demonstrar de forma mais objetiva e clara, a Ilustração 4 aponta o número percentual de áreas verdes (setores) da empresa.

Ilustração 4 - Percentual de áreas com sinalização verde da Tabela 1 (farol)

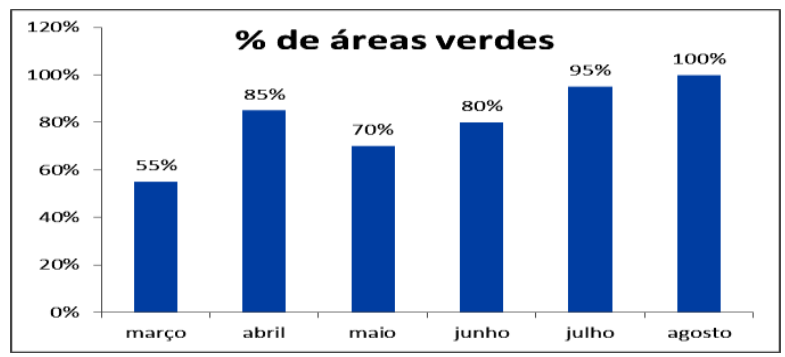

Fonte: Elaborado pelo autor (2016).

É notável o crescimento do número de setores com sinalização verde após variação no início. Isto significa que há uma grande diminuição das não conformidades encontradas nos setores apontadas desde a primeira aplicação, a Ilustração 5 representa a média das notas de todas as áreas da empresa, referentes aos meses de março, maio e agosto. Pode-se observar que os números de não conformidades foram diminuindo aos poucos em todos os meses analisados. Sendo assim, é notável a importância de avaliar e aplicar as boas práticas de fabricação eliminando possíveis riscos de contaminação biológica, física e química, pragas, contaminação cruzada e contaminação de embalagens. Cabe ressaltar que em todos os meses o banco de questões do checklist, visa sempre melhorar os setores continuamente, pois sempre há algo a se melhorar e inovar. 
Ilustração 5 - Média das notas dos checklist.

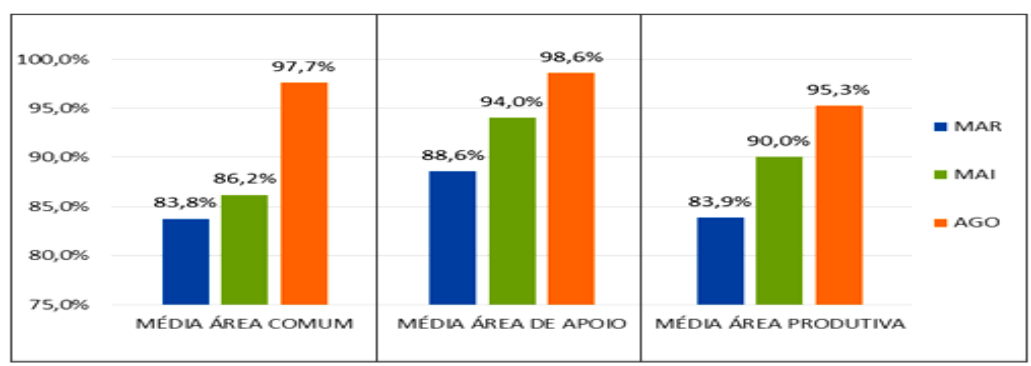

Fonte: Elaborado pelo autor (2016).

As equipes de controle da qualidade foram treinadas para analisar e observar ocorrências de BPF's que os colaboradores acabam descumprindo. Cada setor tem suas normas, diretrizes e condutas a serem seguidas e, por esse motivo, se alguém descumprir, o analista imediatamente anota o setor de ocorrência e o nome completo do colaborador para que depois, no final do mês, seja realizada uma reunião com os colaboradores a fim de ressaltar sobre as ocorrências apontadas no mês e advertir aqueles que causaram a ocorrência para que não aconteça mais.

A Ilustração 6 demonstra a quantidade de ocorrências apontadas pelos analistas.

Ilustração 6 - Ocorrências de BPF

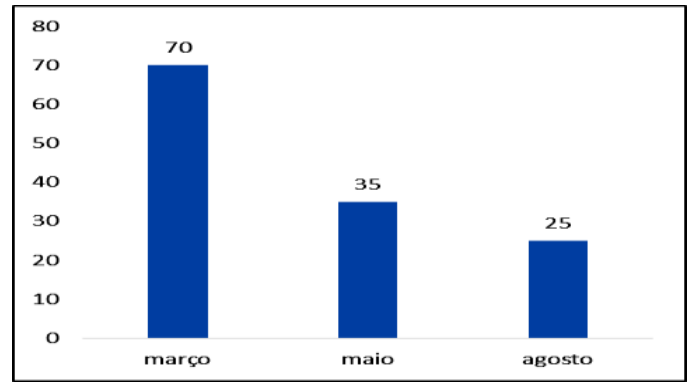

Fonte: Elaborado pelo autor (2016).

Nota-se que houve uma grande diminuição nas ocorrências de BPF, visto que os colaboradores estão sempre recebendo instruções e treinamentos para trabalhar de forma correta, evitando quaisquer problemas relacionados à sua própria segurança e a qualidade e segurança dos alimentos.

Um impacto a ser levado em consideração são as ocorrências do caso SAC (Serviço Atendimento Consumidor), nas quais houve uma redução no índice de ocorrências por segurança alimentar (bolor, pragas, artefatos, tamanho grão, sabor). A Ilustração 7 representa as ocorrências apontadas nos meses de março até agosto de 2016, relacionando as unidades vendidas com os problemas apontados no mês e seu índice é em partes por milhão (PPM). 
Ilustração 7 - Índice de Ocorrência Segurança Alimentar

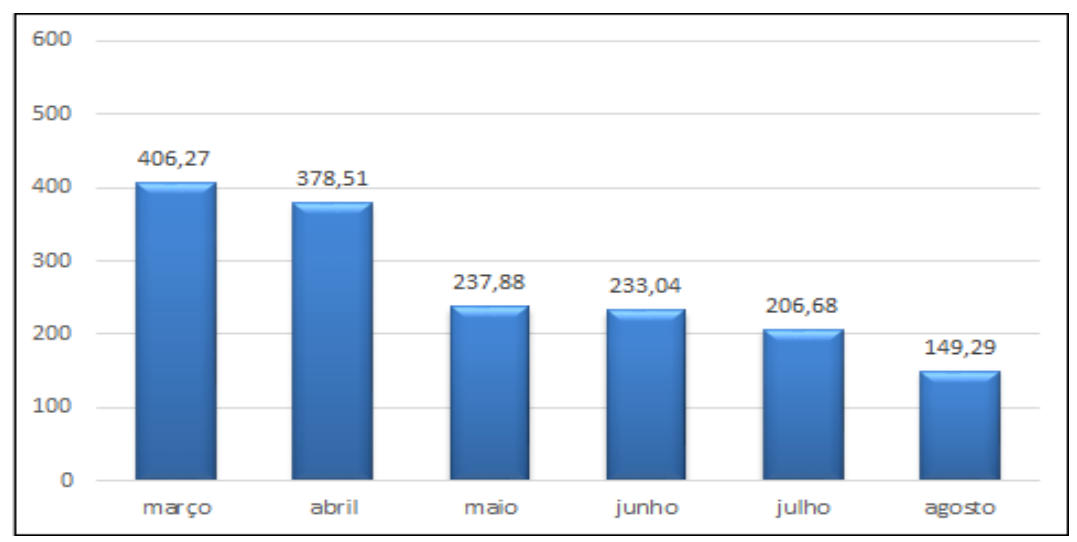

Fonte: Elaborada pelo autor (2016).

Vale lembrar que os resultados só serão observados com mais precisão aproximadamente nove meses após a implantação do manual das boas práticas de fabricação, visto que os alimentos produzidos têm sua validade de doze meses. Dessa forma por enquanto os resultados positivos ainda não são tão notáveis.

A implementação das BPF tem objetivos básicos:

- a unificação dos procedimentos que resulta em produtos acabados dentro das especificações;

- e demonstrar que a empresa se encontra em estágio superior na qualidade.

Por isso é visível os resultados obtidos nos parâmetros analisados neste estudo.

Em pesquisa realizada na Resvista Pet Food Brasil, pag. 20 e 22 - Edição 20 maio/junho 2012; fabricantes de alimentos para cães e gatos identificou-se que as oportunidades de melhorias para a implantação das BPF eram as questões relacionadas aos hábitos higiênicos e ao programa de treinamento de pessoal.

No presente estudo de caso, verificou-se que o investimento em treinamentos dos colaboradores, a elaboração de cartilha com linguagem de fácil entendimento, contendo figuras e o comprometimento dos gestores, foram fundamentais para o sucesso da implantação das BPF's.

Para garantir ainda mais segurança e qualidade nos alimentos produzidos, em 2017 será implantado na empresa o sistema de análise de perigo e ponto crítico de controle (APPCC). Este sistema é uma técnica preventiva de controle de qualidade e que foi desenvolvido para fornecer dados sobre perigos potenciais de um alimento, ainda em processamento, e quais as ações corretivas a serem tomadas. 


\section{CONCLUSÃO}

Com o presente trabalho realizado, pode-se verificar a importância da implantação das BPF em uma empresa produtora de alimentos. A implantação das BPF é considerada a base do controle de qualidade em uma empresa alimentícia. É um processo contínuo que nunca deve cessar, sempre havendo adaptações e inovações que buscam a melhoria contínua dos produtos e do estabelecimento.

Embora os funcionários tenham recebido treinamento de capacitação de BPF durante a realização do trabalho, é de fundamental importância que esses treinamentos se repitam, como forma de relembrar a importância que as BPF representam e as normas básicas que devem ser seguidas. O método utilizado para a implantação das BPF foi prático e funcional, permitindo que as não conformidades fossem identificadas rapidamente e regularizadas de forma organizada e objetiva. Foi construída uma nova visão do significado de qualidade. Funcionários e direção foram estimulados a seguir trabalhando em função da melhoria contínua.

Conclui-se então, que a implantação das BPF nesta empresa foi executada com sucesso, atingindo os objetivos propostos, observando o quanto é complexa a implantação na íntegra das BPF e que há necessidade de melhorias constantes, utilizando-se ferramentas da qualidade e sistemas de gestão que garantem com eficácia à inovação, a melhoria contínua, a qualidade e a segurança alimentar, trazendo assim a satisfação dos pets e dos seus proprietários.

\section{REFERÊNCIAS}

ALMEIDA, Marcio. BPF - Boas Práticas de Fabricação. Qualy - Engenharia da Qualidade. 2012. Disponível em: <http://marcioqualy.blogspot.com.br/2012/07/bpf-boas-praticas-defabricacao.html>. Acesso em 13 de maio de 2017.

ANVISA, Ministério da Saúde. Agência Nacional de Vigilância Sanitária. Portaria no 216, de 15 de setembro de 2004. Regulamento técnico de boas práticas para serviços de alimentação. Brasília, Diário Oficial da União, 15 set. 2004. Disponível em: <http://portal.anvisa.gov.br/documents/33916/388704/RESOLU\%25C3\%2587\%25C3\%2583 $\mathrm{O}-$

RDC\%2BN\%2B216\%2BDE\%2B15\%2BDE\%2BSETEMBRO\%2BDE\%2B2004.pdf/237014 96-925d-4d4d-99aa-9d479b316c4b>. Acesso em 13 de maio de 2017 
ARAUJO, Felipe - $\quad$ Auditoria da Qualidade. Disponível em: $<$ https://www.infoescola.com/administracao_/auditoria-da-qualidade>. Acesso em 16 de maio de 2017.

LIMA, Leandra de Jesus, LIMA, Robernei Ap. A importância das auditorias internas nas organizações. Disponível em:

$<$

http://www.portaldecontabilidade.com.br/tematicas/auditoria-interna-organizacoes.htm >. Acesso em 04 de abril de 2017

GOUVÊA, Eng. Edilson M. da. Checklist como Ferramenta de Qualidade para Soluções de Problemas. Domingo, 13 de março de 2011. Disponível em: $<$ http://improveeng.blogspot.com.br/2011/03/check-list-como-ferramenta-dequalidade.html>. Acesso em 18 de maio de 2017.

MAPA, Ministério da Agricultura, Pecuária e Abastecimento. Instrução normativa no 4, de 23 de fevereiro de 2007. Regulamento técnico sobre as condições higiênico-sanitárias e de boas práticas de fabricação para estabelecimentos fabricantes de produtos destinados à alimentação animal e o roteiro de inspeção. Diário Oficial, Brasília, 01 mar. 2007, Seção 1.

MAPA - Ministério da agricultura, pecuária e abastecimento. Instruções Normativas No. 04 e 65. Disponível em <http://www.agricultura.gov.br>. Acesso em 15 de maio de 2017.

PAULA, Gilles B. de. Indicadores de Desempenho - O Guia definitivo para sua empresa! Parte I. 07 de junho de 2015. Disponível em <http://www.treasy.com.br/blog/indicadores-dedesempenho>. Acesso em 16 de maio de 2017.

Revista Pet Food Brasil, Editora Stilo. São Paulo; ano 7/Edição 37/Mar-Abr e Edição 38/MaiJun/2015; ano 8/Edição 43/Mar-Abr/2016. Disponível em:<www.editorastilo.com.br >. Acesso em 16 de maio de 2017.

SINDIRAÇÕES. Boletim Informativo do Setor de Alimentação Animal, dezembro de 2015. Disponível em: <http://sindiracoes.org.br/wpo-content/uploads/2015/12/boletim_ informativo_do_setor_de_alimentacao_animal_dez2015_online.pdf $>$. Acesso em: 16 de maio de 2017.

SINDIRAÇÕES. Compêndio brasileiro de alimentação animal, 3ª . Ed., São Paulo, 873 p., 2009.

SOTILLE, Mauro. Garantia da Qualidade versus Controle da Qualidade. 05 de fevereiro de 2014. Disponível em: < http://dicasgp.pmtech.com.br/garantia-vs-controle-da-qualidade >. Acesso em 15 de maio de 2017. 